\title{
White matter fractional anisotropy is related to processing speed in metabolic syndrome patients: a case-control study
}

\author{
Bàrbara Segura ${ }^{1}$, María Ángeles Jurado ${ }^{1,2^{*}}$, Núria Freixenet ${ }^{3}$, Núria Bargalló ${ }^{4,5}$, Carme Junqué ${ }^{1,5}$, Adrià Arboix $^{6}$
}

\begin{abstract}
Background: Metabolic Syndrome (MetSd) is a cluster of vascular risk factors that may influence cerebrovascular pathology during aging. Recently, microstructural white matter (WM) changes detected by diffusion tensor imaging (DTI) and processing speed deficits have been reported in MetSd patients. We aimed to test the relationship between WM alteration and cognitive impairment in these patients.

Methods: The sample comprised 38 subjects (19 patients aged between 50 and 80 years old, and 19 controls). All patients fulfilled National Cholesterol Education Program Adult Treatment Panel III (NCEP ATP-III) criteria for MetSd. Speed of information processing was measured by the Symbol Digit Modalities Test (SDMT) and reaction time (RT) on the Continuous Performance Test (CPT-II) and the Grooved Pegboard Test (GPT). DTI images were acquired in a 3 Tesla Siemens Trio scanner. Voxelwise statistical analysis of the fractional anisotropy (FA) data was performed using the Tract-Based Spatial Statistics part of the FMRIB Software Library. A correlation analysis was performed between processing speed variables and FA values.
\end{abstract}

Results: There was a larger proportion of slow subjects (percentile below $\left.25^{\text {th }}\right)$ in the patient group $\left(\mathrm{Chi}^{2}=7.125\right.$ $p=0.008)$. FA values correlated positively with SDMT in anterior and posterior parts of the corpus callosum, and RT CPT-II correlated negatively with FA values in the anterior corpus callosum ( $p<0.05$ corrected) in the patient group.

Conclusion: We found significant correlations between WM alterations and cognitive impairment in MetSd patients, especially in the frontal lobe. These findings highlight the importance of MetSd prevention and control due to its association with structural and functional damage in the central nervous system.

\section{Background}

Metabolic Syndrome (MetSd) is a cluster of risk factors including hypertension, hyperglycemia, dyslipidemia, and central obesity associated with cardiovascular disease. The prevalence of MetSd is increasing in modernday societies and the condition is now very common during aging [1].

Recent DTI studies have shown region-specific patterns of WM alterations, such as myelin loss and axon degeneration in humans $[2,3]$ and animals $[4,5]$.

Among the DTI indexes, FA has been defined as a measure of tract directionality and integrity. Decreases

\footnotetext{
* Correspondence: majurado@ub.edu

'Department of Psychiatry and Clinical Psychobiology. Faculty of Psychology. University of Barcelona. Barcelona. Spain
}

(C) 2010 Segura et al; licensee BioMed Central Ltd. This is an Open Access article distributed under the terms of the Creative Commons Attribution License (http://creativecommons.org/licenses/by/2.0), which permits unrestricted use, distribution, and reproduction in any medium, provided the original work is properly cited.

in FA have been observed in association with aging [6], especially in the frontal lobe [7]. Moreover, FA decrease has been related with changes in other diffusion measures such as axial diffusivity (AD), radial diffusivity (RD) and mean diffusivity (MD). The specific combinations of these variables are related to microstructural deterioration mechanisms in ageing. For instance chronic WM degeneration, demyelination, subtle microstructural alterations, secondary Wallerian degeneration and gliosis or early axonal injury [2].

In spite of the increasing importance of MetSd in the aging process, the association of the condition with brain damage and cognitive performance has not been widely studied.

Previous magnetic resonance imaging (MRI) studies report some evidence of the effect of MetSd on the 
brain, especially in WM. These studies describe the presence of periventricular hyperintensities, subcortical WM lesions [8] and silent lacunar infarcts [9] in MetSd samples. In a recent DTI study [10] of MetSd patients, we found an anterior-posterior pattern of deterioration in WM with reduced fractional anisotropy (FA) and increased apparent diffusion coefficient (ADC) values.

The presence of microangiopathies is frequent in the elderly and constitutes an independent risk factor for recurrent vascular events and cognitive impairment. Today, there is growing interest in the study of the early phases of small vessel disease, and the follow-up of prodromal states of pathology may help to identify the factors that influence the progression.

Moreover, some authors associate MetSd in aging with high risk of dementia [11], fronto-subcortical symptoms $[12,13]$ and poorer neuropsychological performance $[14,15]$. In a recent study, we found differences between MetSd and control groups in processing speed and in some executive functions, after controlling for the influences of education and gender[15]. Our results suggested that MetSd may be a prodromal state of vascular cognitive impairment. In recent studies, slower processing speed in MetSd patients is the most consistent finding [16], even when the subjects are relatively young [15].

To the best of our knowledge, the relation between WM alterations and neuropsychological profile in MetSd patients has not been studied to date.

Relationships between the loss of WM integrity and slowed processing speed have been shown in healthy people [17] and neurological disorders, and the importance of corpus callosum preservation in good signal transduction has been stressed [18]. Processing speed is a basic cognitive or brain processes that subserves many other higher-order cognitive domains. The speed with which an individual performs a cognitive activity is not simply a function of the processes required in that activity but also a reflection of his or her ability to carry out many different types of processing operations. Slowing with age is often considered one of the best-documented and least controversial behavioural phenomenon of aging [19]. As a basic process that is dependent on basic neuronal function and glial support, any sort of focal or diffuse injury to the brain can affect processing speed. In central nervous system oligodendrocytes are the glial cell responsible to myelin sheath formation. Myelin acts as insulator and it accelerates the neural signal through the axons, therefore it is crucial to modulate the speed of signal transduction [20]. When WM is disrupted then processing speed is in danger to be affected $[18,21]$.

In this study, we hypothesize that MetSd slowness, evidenced by neuropsychological assessment, would be associated with subtle FA decreases. To test this possibility we performed a correlation study between FA and processing speed variables using DTI.

\section{Methods \\ Subjects}

The study included thirty-eight subjects from two public medical centers in Cerdanyola del Vallés and Sant Just Desvern in the province of Barcelona (Spain). The present sample participated in two previous works $[10,15]$

We recruited 19 MetSd and 19 controls. To be diagnosed with MetSd, participants had to fulfill at least 3 out of 5 criteria listed in Table 1 (NCEP criteria) [22]. The criterion for selecting controls was the absence of any vascular risk factors included in the MetSd criteria. All the participants were volunteers, right-handed, and aged between 50 and 80 years old. The exclusion criteria for both groups and details of the methods used have been explained elsewhere [2].

The sample comprised a patient group of eleven women and eight men with mean age 61.26 years $(\mathrm{SD}=$ 7.19) and mean years of education $10.37(\mathrm{SD}=3.55)$, and a control group of eleven women and eight men with mean age 59.63 years $(\mathrm{SD}=5.37)$ and mean years of education $11.68(\mathrm{SD}=3.59)$.

All enrolled subjects gave written informed consent prior to taking part in the study, and the research was conducted in accordance with the Helsinki Declaration. The study was approved by the ethics committee of the University of Barcelona.

\section{Neuropsychological examination}

All participants underwent a comprehensive neuropsychological examination performed by a trained neuropsychologist (B.S.). Intelligence quotient was estimated

\section{Table 1 Metabolic Syndrome criteria}

\begin{tabular}{ll}
\hline Measure & Categorical Cut-off points \\
\hline Elevated waist & $\geq 102 \mathrm{~cm}$ in men \\
circumference & $\geq 88 \mathrm{~cm}$ in women \\
Elevated triglycerides & $\geq 150 \mathrm{mg} / \mathrm{dL}$ \\
& or \\
& On drug treatment for elevated triglycerides \\
Reduced HDL-Cholesterol & $<40 \mathrm{mg} / \mathrm{dL}$ in men \\
& $<50 \mathrm{mg} / \mathrm{dL}$ in women \\
& or \\
& On drug treatment for reduced HDL- \\
& cholesterol. \\
& $\geq 130 \mathrm{~mm}$ Hg systolic blood pressure \\
& or \\
& $\geq 85 \mathrm{~mm}$ Hg diastolic blood pressure \\
Elevated blood pressure & or \\
& On antihypertensive drug treatment. \\
& $\geq 100 \mathrm{mg} / \mathrm{dL}$ \\
& or \\
& On drug treatment for elevated glucose. \\
\hline
\end{tabular}

HDL: High density lipoproteins 
using Vocabulary subtest of Wechsler Adults Intelligence Scale-III.

Several criteria have been proposed to guide the selection of measures used to assess processing speed: relative simple task, the speed measure should not merely represent the input and output processes or sensory and motor processes, it is desirable that the construct be evaluated with several measures to minimize the specific variance associated with single measures and to emphasize common construct-relevant variance [19].

We selected processing speed test in base of their sensibility to processing speed changes in previous studies. The processing speed variables used to test our hypothesis were total correct responses in 90s on the orallyadministered SDMT [23], and time taken to complete the GPT with dominant and non-dominant hands [23] and RT on the CPT-II[23].

All the selected tests provide measures of processing speed. Specifically, the oral SDMT test also involves divided attention, complex visual scanner tracking, perceptual speed and memory. The use of the oral version avoids motor influences in this processing speed measure. GPT involves eye-hand coordination and motor speed: some studies have shown slowed GPT execution in patients with vascular risk factors $[24,25]$. Finally, CPT-II assesses sustained attention to a visual-motor task and response inhibition. RT measures in this latter task show the mean response time to the targets [26], the computerized reaction time measures allow obtaining higher accuracy. All the variables were recorded as part of a more extensive neuropsychological assessment described elsewhere [15].

\section{MRI data acquisition}

Data acquisition was performed on a 3 Tesla Siemens Magnetom Trio scanner (Erlangen, Germany), belonging to the Institut d'Investigacions Biomèdiques August Pi $i$ Sunyer (IDIBAPS), at the Radiology Service of the Hospital Clínic of Barcelona. The DTI sequences were acquired with the following parameters: $\mathrm{TR}=5533 \mathrm{~ms}, \mathrm{TE}=88$ ms, acquisition matrix $=122 \times 122$, field of view $(\mathrm{FOV})=$ $250 \times 250 \mathrm{~mm}^{2}$, diffusion directions $=30$, slice thickness $=2 \mathrm{~mm}$, gap distance $=0.6 \mathrm{~mm}$, number of slices = 44, b-values: 0 and $1000 \mathrm{~s} / \mathrm{mm}^{2}$, IPAT factor $=2$, total scan time 3:10 min.

\section{Image pre-processing}

Voxelwise statistical analysis of the FA data was carried out using Tract-Based Spatial Statistics, [27], part of the FMRIB Software Library [28]. First, FA images were created by fitting a tensor model to the raw diffusion data using FDT, and then brain-extracted using BET [29]. FA data for all subjects were then aligned into a common space using the nonlinear registration tool FNIRT
$[30,31]$ which uses a b-spline representation of the registration warp field [32]. Next, the mean FA image was created and thinned to produce a mean FA skeleton (FA threshold to 0.2) which represents the centers of all tracts common to the group (control or patient). The aligned FA data for each subject were then projected onto this skeleton and the resulting data fed into voxelwise cross-subject statistics (permutation-based, 5000 permutations).

\section{Assessment of white matter hyperintensity (WMH) burden} The DTI sequence also provides a T2 weighted volume (B0) which was used to assess WMH. Briefly, a boardcertified neuroradiologist (N.B) rated all images using the Fazekas scale [33]. The scale is labeled as $0=$ absence, 1 = punctate foci, 2 = beginning confluent of foci, 3 = large confluent areas.

\section{Statistical analysis}

For the analysis of the neuropsychological data, raw data were first transformed into percentile ranks (pc). The transformation of raw to percentile scores allows us to define the threshold which determines slow performance on cognitive tests in the study-sample (percentile $=25$ ) in comparison to the normative population. This threshold allows us to detect the amount of subjects with scores in the fourth quartile of normal distribution.

A qualitative variable was created for each neuropsychological quantitative variable indicating the frequency of slow participants.

Demographic and neuropsychological variables and the presence of WMH in the groups were compared using the Statistical Package for the Social Sciences (SPSS WIN; v.14.0). The Mann Whitney U test was used for quantitative variables when required, while the $\chi^{2}$ test was used to analyze qualitative variables. A $\mathrm{p}$ value $<0.05$ was considered statistically significant.

Correlations between DTI values and processing speed variables were examined in the patient and control groups using the FMRIB software library's randomized TFCE (Threshold-Free Cluster Enhancement) option [34]. In our analyses we used default settings for TFCE and performed 5000 permutations. A standard general linear model design matrix was applied using raw scores. Results were reported at $\mathrm{p}$ values $<0.05$, corrected. To control the possible effect of age within group correlations, we performed post-hoc partial correlation analysis between the mean FA of significant cluster and processing speed variable.

\section{Results}

There were no differences between the groups in age, years of education, intelligence quotient estimation or gender (Table 2). All participants were from the same 
Table 2 Demographic data comparison between groups

\begin{tabular}{|c|c|c|c|c|c|c|}
\hline & $\begin{array}{l}\text { Metabolic } \\
\text { Syndrome }\end{array}$ & & Control & & & \\
\hline & Mean (SD) & Range & Mean (SD) & Range & $U$ & $\begin{array}{l}p \\
\text { value }\end{array}$ \\
\hline Age (years) & $61.26(7.19)$ & $50-75$ & $59.63(5.37)$ & $51-67$ & 160.5 & 0.563 \\
\hline $\begin{array}{l}\text { Education } \\
\text { (years) }\end{array}$ & $10.37(3.55)$ & $5-16$ & $11.68(3.59)$ & 8-16 & 138.5 & 0.223 \\
\hline Vocabulary & $42.21(8.651)$ & $28-58$ & $42.89(9.427)$ & $25-60$ & 168.5 & 0.729 \\
\hline
\end{tabular}

S.D: standard deviation, U: Mann Whitney $\mathrm{U}$ test.

geographical area. There were no significant differences between groups in the period between psychological testing acquisition and the scan session $(\mathrm{t}=1.27 \mathrm{p}=$ 0.312 ). Mean time in days between both sessions was mean $75.95(\mathrm{SD}+81.02)$ in patients and mean 108.21 (S.D+110.40) in controls.

The neuropsychological examination of all controls showed normal cognitive performance in comparison with standard population scores. This result ruled out the possibility of cognitive impairment in any of our subjects. Patients and controls showed WMH, typically described in older samples, but there were no differences between the rates of WHM in the two groups $\left(\mathrm{Chi}^{2}=2.182 \mathrm{p}=0.336\right)$.

Comparison of neuropsychological raw data did not reveal significant differences between groups, even in processing speed variables (data previously reported in [2]. However, SDMT and GPT ND identified significantly larger proportion of slow-performance subjects (pc $<25)$ in the patient group (Table 3). No significant differences were found comparing the other processing speed variables.

In the patient group, FA correlated positively with SDMT in anterior (Table 4 and Figure $1 \mathrm{C}$ ) and posterior (Table 4 and Figure 1A and Figure 2,3) regions of the corpus callosum. RT CPT-II correlated negatively with FA values in the anterior part of the corpus callosum (Table 4 Figure 1B and Figure 4). No significant results were found in the control group or in the inverse contrast. No significant results where found between groups in FA values (significant coordinates from correlation analysis). The correlation analysis did not show significant results in the other variables.

Age is a well known variable related to processing speed, to control the possible effect of this variable in the correlation analysis within each group, we performed a partial correlation analysis between the mean FA value for each significant cluster and the processing speed measures. We obtained significant results in correlation analysis between SDMT and mean FA measures in the significant clusters, whilst the correlation between mean FA measure and CPT II RT show a tendency in the significant cluster (Table 5).

\section{Discussion}

Previous studies have reported relationships between MetSd and slower processing $[15,16]$ and subtle microstructural alterations in WM [10]. In the present study, there were more slow participants in MetSd group than in controls group, and their performance correlated with the FA values obtained by DTI. The correlations were especially significant in the corpus callosum fibers of the frontal lobe.

In a study of diabetic patients (type I) Kodl et al. (2009) [35] reported an association between FA measures in the corpus callosum splenium, corona radiata and optic radiation with time taken to copy Rey's figure and Grooved Pegboard Test scores. These results indicated a specific effect of a vascular risk factor in regions involved in processing speed. A recent functional MRI study of the oral version of the SDMT reported the involvement of anterior and posterior brain areas in the task, specifically the occipital lobes (related to the perception of visual attention/scanning) and the fronto-parietal network. The authors associated these latter areas with processing speed, attention and working memory, all processes involved in SDMT performance [36]. Similarly, Madden et al. (2009) [37] showed that correlations between FA and RT of several behavioral measures were not entirely dependent on perceptual-motor processing

Table 3 Cognitive test results

\begin{tabular}{|c|c|c|c|c|c|c|c|c|}
\hline \multirow[b]{2}{*}{ Cognitive Test } & \multicolumn{3}{|c|}{ Metabolic Syndrome } & \multicolumn{5}{|l|}{ Control } \\
\hline & Mean(SD) & Range & $\mathrm{Pc}<25$ & Mean(SD) & Range & $\mathrm{Pc}<25$ & $\mathrm{Chi}^{2}$ & $p$ value \\
\hline SDMT & $\begin{array}{l}42.63 \\
(15.90)\end{array}$ & $19-61$ & 6 & $\begin{array}{l}49.58 \\
(11.57)\end{array}$ & $31-68$ & 0 & 7.135 & 0.008 \\
\hline GPT DH & $\begin{array}{l}88.53 \\
(37.88)\end{array}$ & $59-221$ & 7 & $\begin{array}{l}72.16 \\
(12.81)\end{array}$ & $59-110$ & 3 & 2.171 & 0.141 \\
\hline GPT NDH & $\begin{array}{l}99.74 \\
(41.63)\end{array}$ & $62-233$ & 8 & $\begin{array}{l}81.95 \\
(24.22)\end{array}$ & $55-170$ & 2 & 4.886 & 0.027 \\
\hline CPT-II RT & $\begin{array}{l}440.53 \\
(71.33)\end{array}$ & $329-557$ & 8 & $\begin{array}{l}422.01 \\
(55.23)\end{array}$ & $322-487$ & 7 & 0.110 & 0.740 \\
\hline
\end{tabular}

SDMT = Symbol Digit Modalities Test; GPT = Grooved Pegboard Test, DH = Dominant Hand, NDH = Non Dominant Hand; CPT-II RT = Continuous Performance Test Reaction time; Pc = Percentile; $\mathrm{Chi}^{2}=$ Chi square test. 
Table 4 Anatomical regions, where FA correlated with cognitive performance in the MetSd group

\begin{tabular}{|c|c|c|c|c|c|c|c|c|}
\hline \multirow[t]{2}{*}{ Cognitive test } & \multirow[t]{2}{*}{ Corpus Callosum region } & \multirow[t]{2}{*}{ Lobe } & \multirow[t]{2}{*}{ Size } & \multicolumn{3}{|c|}{ MNI coordinates } & \multirow{2}{*}{$\begin{array}{l}\text { p value } \\
\text { (corr) }\end{array}$} & \multirow[t]{2}{*}{$r$} \\
\hline & & & & $x$ & $y$ & $z$ & & \\
\hline \multirow[t]{2}{*}{ SDMT } & Right Anterior & $\mathrm{F}$ & 8419 & 21 & 29 & 28 & 0.016 & 0.8 \\
\hline & Left Posterior & $0-\mathrm{T}$ & 11331 & -33 & -44 & 9 & 0.015 & 0.7 \\
\hline \multicolumn{9}{|l|}{ CPT-II RT } \\
\hline & Left Anterior & $\mathrm{F}$ & 25171 & -17 & 26 & 22 & 0.003 & 0.7 \\
\hline
\end{tabular}

SDMT = Symbol Digit Modalities Test; CPT-II = Continuous Performance Test II; RT = Reaction time; $\mathrm{F}=$ Frontal; O = Occipital; $\mathrm{T}=$ Temporal; Size = Cluster size at p 0.05; corr $=$ Corrected; $r=$ Pearson coefficient

and may reflect deficits in decision-level processing associated with age-related decline in WM integrity within specific regions of the fronto-parietal network (central genu and splenium-parietal fasciculi).

Similarly, the anterior-posterior WM involvement in our results may also reflect the influence of these regions in attention and executive processing in the context of visuomotor control and response regulation, especially in SDMT and RT CPT-II tasks in which these processes are more directly involved. In fact, greater callosal integrity allows faster task performance, as a result of better signal transduction.

Mental slowness also correlated with extended atrophy in the corpus callosum in normal aging [38] and in subjects with WMH [21], reflecting the relationship between mental slowness and subcortical white matter damage.

Recent studies in the elderly corroborate our neuropsychological and DTI findings, showing associations between WM degeneration and slower processing speed and executive deficits, specifically in the frontal lobe [17]. Madden et al (2004) [39] also emphasized the importance of anterior and posterior corpus callosum in processing speed performance in an adult sample; in younger adults the best predictor of RT was FA values in the splenium of the corpus callosum, while in the elderly it was FA in the anterior limb of the internal capsule.

The studies reported above showed a relation between the corpus callosum and processing speed and attention in the elderly. Although most of these studies controlled the history of cardiovascular pathology and the effects of certain vascular risk factors (hypertension, presence of $\mathrm{WMH}$, diabetes mellitus), they did not control the presence of other risk factors included in the MetSd diagnosis such as obesity, insulin resistance and dyslipidemia. Despite the fact that the relation between processing speed measures and FA are influenced by age, our

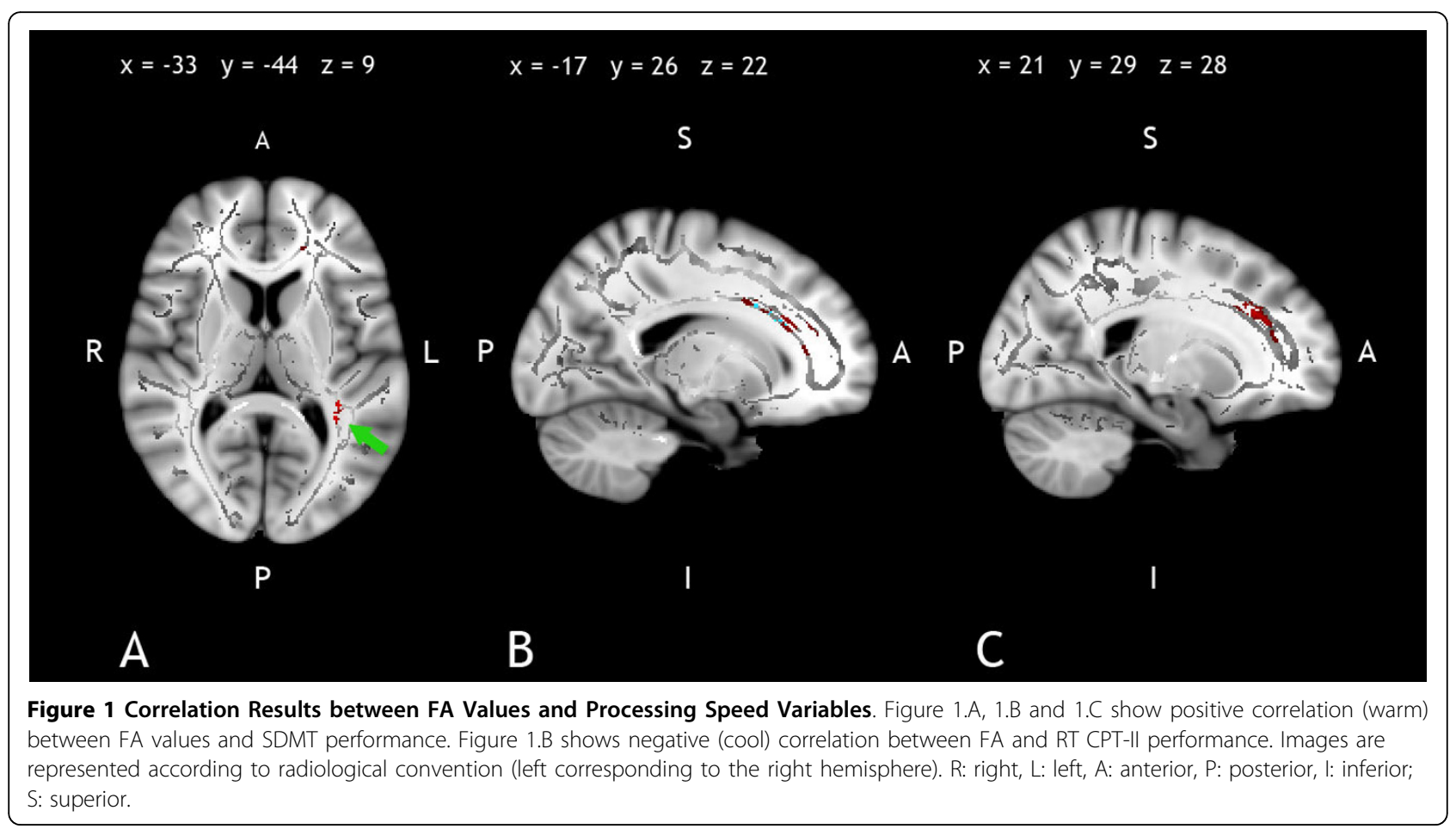




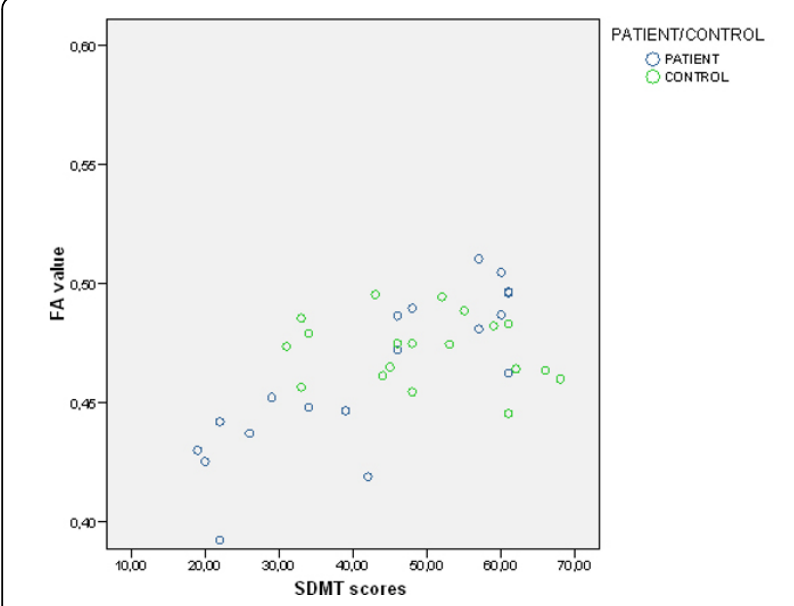

Figure 2 FA values and SDMT scores (for both patients and controls) in $\mathbf{2 1}, \mathbf{2 8}, 29$ coordinate significant cluster. $Y$ axis FA

value in $21,28,29$ coordinate cluster. $X$ axis SDMT scores.

results suggest that this relation between processing speed deficits and WM alterations in the elderly could be mediated in some way by the effect of MetSd; since this relationship was found only in our MetSd patients, and it was maintained after the post-hoc analysis controlling the possible age effect. Although the specific mechanism underlying this relationship is not clear, small-vessel disease may be responsible for the microstructural alteration in these patients due to the chronic state of vascular dysregulation in the brain [40] and blood brain barrier failure [41]. Some authors have suggested this relationship between vascular risk factors and pathological pathways such as ischemic cerebral small-vessel disease, as well as a toxic effect on neurons caused by the accumulation of advanced glycation end

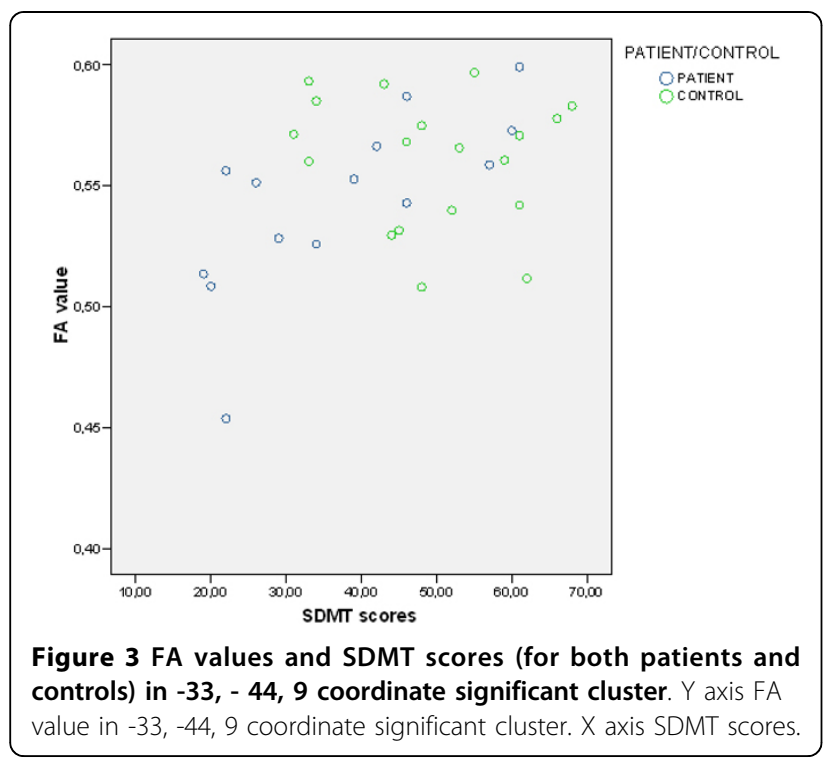

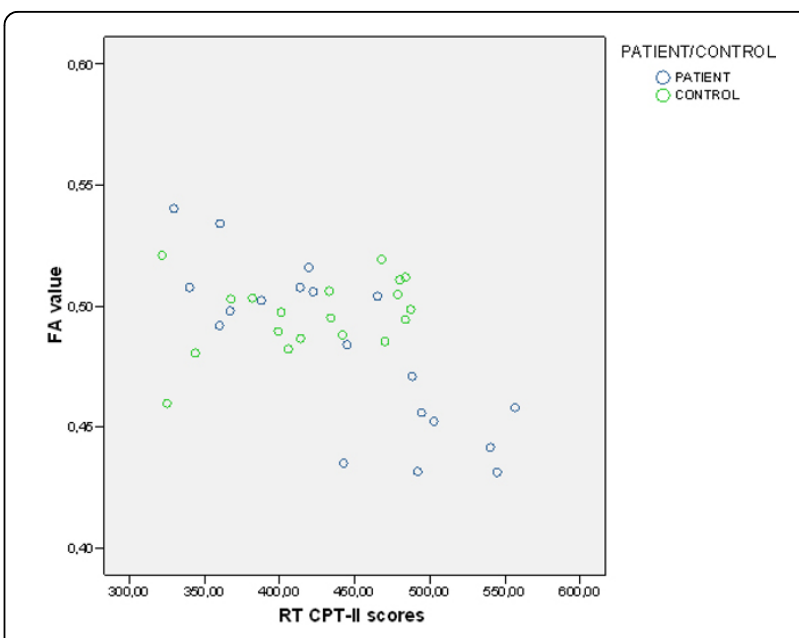

Figure 4 FA values and RT CPT-II scores (for both patients and controls) in $-17,26,22$ coordinate significant cluster. $Y$ axis $F A$ value in $-17,26,22$ coordinate cluster. X axis RT CPT-II scores.

products and their influence on neurodegenerative mechanisms. Therefore, vascular risk factors included in MetSd may influence both cerebrovascular pathology and neurodegenerative processes [42].

Vascular risk factors are very common in aging, but when they are present in MetSd they may predispose to pathological processes and produce a very early state of deterioration, which makes successful aging more difficult [43].

DTI is a technique that allows early detection of WM damage, sometimes even in regions that appear normal on conventional anatomical images. The present study shows that the relationship between DTI measures and cognitive performance allows detection of structural and functional deficits at an initial state of deterioration, when patients are prodromal for mild vascular cognitive impairment. To the best of our knowledge, our results are the first evidence of vascular involvement in the neuropsychological performance of MetSd patients detected by means of neuroimaging.

Table 5 Partial Correlation analysis between mean FA (within the significant clusters) and cognitive performance in the MetSd group, controlling age effect

\begin{tabular}{lllllll}
\hline Cognitive test & $\begin{array}{l}\text { Corpus Callosum } \\
\text { region }\end{array}$ & MNI coordinates & p value & $\mathbf{r}$ \\
\hline \multirow{2}{*}{ SDMT } & Right Anterior & $\mathbf{x}$ & $\mathbf{y}$ & $\mathbf{z}$ & & \\
& Left Posterior & -33 & -44 & 9 & 0.002 & 0.7 \\
CPT-II RT & & & & & & \\
& Left Anterior & -17 & 26 & 22 & 0.051 & 0.4 \\
\hline
\end{tabular}

SDMT = Symbol Digit Modalities Test; CPT-II $=$ Continuous Performance Test II; $\mathrm{RT}=$ Reaction time; $\mathrm{F}=$ Frontal; $\mathrm{O}=$ Occipital; $\mathrm{T}=$ Temporal; $\mathrm{r}=$ Pearson coefficient. 
Although our findings are suggestive, the study is limited in several ways. The most important limitation is the sample size, due to the high comorbidity of MetSd and aging with some of the exclusion criteria such as vascular pathology. Moreover, the increase of sample size as well as the inclusion of a control group with one or two vascular risk factors in future work would facilitate the analysis of the synergic effects of the vascular risk factors that comprise MetSd. In addition, as our design is cross-sectional, follow-up studies of these patients may show how the profile of cognitive impairment and brain damage evolves using longitudinal designs.

In conclusion, our study found correlations between microstructural WM changes and processing speed deficits in MetSd patients using DTI. These results suggest the existence of a relation between the presence of vascular risk factors and cognitive performance in MetSd patients. Although other factors contribute to pathological aging, MetSd in normal aging may be involved in these processes and may increase the vulnerability to pathology.

The prevalence of MetSd is increasing in modern-day society and its effect is particularly serious in the elderly. Our results highlight the importance of preventing and controlling MetSd because of its association with structural and functional damage in the WM during aging.

\section{Conclusion}

We found significant correlations between WM alterations and cognitive impairment of MetSd patients, especially in the frontal lobe. These findings highlight the importance of MetSd prevention and control due to its association with structural and functional damage in the WM.

\begin{abstract}
Acknowledgements
This study was supported by the grants 2009 SGR941 From the Generalitat of Catalunya, PSI2008-05803-C02-01/PSIC from the Ministerio de Ciencia e innovación to Dr. Maria Angeles Jurado Luque and the grant Ajuts per la formació en la recerca i la docència to Bàrbara Segura Fàbregas from the University of Barcelona.

Thanks to Dr. Cristina Cabistañ and Dr. Carlota Albuin from the Centre d'Atenció Primària (CAP) Canaletes de Cerdanyola del Vallés (Barcelona, Spain) and Dr. Jesus Muniesa from the Centre d'Atenció Primària (CAP) de Sant Just Desvern (Barcelona, Spain) for patient management.
\end{abstract}

\footnotetext{
Author details

${ }^{1}$ Department of Psychiatry and Clinical Psychobiology. Faculty of Psychology. University of Barcelona. Barcelona. Spain. ${ }^{2}$ Institute for Brain, Cognition and Behavior (IR3C). Faculty of Psychology. University of Barcelona. Barcelona. Spain. ${ }^{3}$ Diabetes, Endocrinology and Nutrition Service. Hospital de Sabadell. Corporació Sanitària Parc Taulí. Barcelona. Spain. ${ }^{4}$ Centre de Diagnòstic per la Imatge Hospital Clínic de Barcelona (CDIC), Hospital Clínic de Barcelona. Barcelona. Spain. ${ }^{5}$ Institute of Biomedical Research August Pi i Sunyer (IDIBAPS), Faculty of Medicine. University of Barcelona. Barcelona. Spain.
}

${ }^{6}$ Cerebrovascular Division, Department of Neurology, Hospital Universitari del Sagrat Cor, University of Barcelona. Barcelona. Spain.

\section{Authors' contributions}

BS contributed to the acquisition of subjects and DTI data, analysis, interpretation of data and preparation of manuscript. MAJ contributed to the study concept and design, analysis and interpretation of data, and preparation of manuscript. $\mathbf{N F}$ contributed to the acquisition of subjects and interpretation of data and preparation of manuscript. NB: contributed to the analyses and quantification of WM hyperintensities interpretation of data and preparation of manuscript. CJ contributed to the study concept and design, analysis and interpretation of data, and preparation of manuscript. AA contributed to the interpretation of data, and preparation of manuscript. All authors read and approved the final manuscript.

\section{Competing interests}

The authors declare that they have no competing interests.

Received: 12 October 2009 Accepted: 27 July 2010

Published: 27 July 2010

\section{References}

1. Grundy SM: Metabolic syndrome pandemic. Arterioscler Thromb Vasc Biol 2008.

2. Burzynska AZ, Preuschhof C, Backman L, Nyberg L, Li SC, Lindenberger U, Heekeren HR: Age-related differences in white matter microstructure: Region-specific patterns of diffusivity. Neuroimage 2010, 49(3):2104-2112.

3. Bennett IJ, Madden DJ, Vaidya CJ, Howard DV, Howard JH Jr: Age-related differences in multiple measures of white matter integrity: A diffusion tensor imaging study of healthy aging. Hum Brain Mapp 2010, 31:378-90.

4. Song SK, Sun SW, Ramsbottom MJ, Chang C, Russell J, Cross AH: Dysmyelination revealed through MRI as increased radial (but unchanged axial) diffusion of water. Neuroimage 2002, 17(3):1429-1436.

5. Song SK, Yoshino J, Le TQ, Lin SJ, Sun SW, Cross AH, Armstrong RC: Demyelination increases radial diffusivity in corpus callosum of mouse brain. Neuroimage 2005, 26(1):132-140.

6. Nusbaum AO, Tang CY, Buchsbaum MS, Wei TC, Atlas SW: Regional and global changes in cerebral diffusion with normal aging. AJNR Am $J$ Neuroradiol 2001, 22(1):136-142.

7. Pfefferbaum A, Adalsteinsson E, Sullivan EV: Frontal circuitry degradation marks healthy adult aging: Evidence from diffusion tensor imaging. Neuroimage 2005, 26(3):891-899.

8. Bokura H, Yamaguchi S, lijima K, Nagai A, Oguro H: Metabolic syndrome is associated with silent ischemic brain lesions. Stroke 2008, 39(5):1607-1609.

9. Kwon HM, Kim BJ, Lee SH, Choi SH, Oh BH, Yoon BW: Metabolic syndrome as an independent risk factor of silent brain infarction in healthy people. Stroke 2006, 37(2):466-470.

10. Segura B, Jurado MA, Freixenet N, Falcón C, Junqué C, Arboix A: White matter changes in metabolic syndrome patients: A diffusion tensor imaging study. Neurology 2009, 73:438-44.

11. Vanhanen M, Koivisto K, Moilanen L, Helkala EL, Hanninen T, Soininen $H$ Kervinen K, Kesaniemi YA, Laakso M, Kuusisto J: Association of metabolic syndrome with Alzheimer disease: a population-based study. Neurology 2006, 67(5):843-847.

12. Roriz-Cruz M, Rosset I, Wada T, Sakagami T, Ishine M, Roriz-Filho JS, Cruz TR, Rodrigues RP, Resmini I, Sudoh S, Wakatsuki Y, Nakagawa M, Souza AC, Kita T, Matsubayashi K: Stroke-independent association between metabolic syndrome and functional dependence, depression, and low quality of life in elderly community-dwelling Brazilian people. J Am Geriatr Soc 2007, 55(3):374-382.

13. Roriz-Cruz M, Rosset I, Wada T, Sakagami T, Ishine M, De Sa Roriz-Filho J, Cruz TR, Hosseinkhani M, Rodrigues RP, Sudoh S, Arai H, Wakatsuki Y, Souza AC, Nakagawa M, Kita T, Matsubayashi K: Cognitive impairment and frontal-subcortical geriatric syndrome are associated with metabolic syndrome in a stroke-free population. Neurobiol Aging 2007, 28(11):1723-1736.

14. Dik MG, Jonker C, Comijs HC, Deeg DJ, Kok A, Yaffe K, Penninx BW: Contribution of metabolic syndrome components to cognition in older individuals. Diabetes Care 2007, 30(10):2655-2660. 
15. Segura B, Jurado MA, Freixenet N, Albuin C, Muniesa J, Junque C: Mental slowness and executive dysfunctions in patients with metabolic syndrome. Neurosci Lett 2009, 462:49-53.

16. van den Berg E, Dekker JM, Nijpels G, Kessels RP, Kappelle $L$, de Haan EH, Heine RJ, Stehouwer CD, Biessels GJ: Cognitive functioning in elderly persons with type 2 diabetes and metabolic syndrome: the Hoorn study. Dement Geriatr Cogn Disord 2008, 26(3):261-269.

17. Kennedy KM, Raz N: Aging white matter and cognition: differential effects of regional variations in diffusion properties on memory, executive functions, and speed. Neuropsychologia 2009, 47(3):916-927.

18. Roosendaal SD, Geurts JJ, Vrenken H, Hulst HE, Cover KS, Castelijns JA, Pouwels PJ, Barkhof F: Regional DTI differences in multiple sclerosis patients. Neuroimage 2009, 44(4):1397-1403.

19. Salthouse TA: The processing-speed theory of adult age differences in cognition. Psychol Rev 1996, 103(3):403-428.

20. Kandel ER, Schwartz JH, Jessell TM: Principios de neurociencia: Cuarta edición. Madrid etc.: McGraw-Hill Interamericana 2001.

21. Jokinen $H$, Ryberg C, Kalska H, Ylikoski R, Rostrup E, Stegmann MB, Waldemar G, Madureira S, Ferro JM, van Straaten EC, Scheltens P, Barkhof F, Fazekas F, Schmidt R, Carlucci G, Pantoni L, Inzitari D, Erkinjuntti T, LADIS group: Corpus callosum atrophy is associated with mental slowing and executive deficits in subjects with age-related white matter hyperintensities: the LADIS Study. J Neurol Neurosurg Psychiatry 2007, 78(5):491-496.

22. Grundy SM, Cleeman Jl, Daniels SR, Donato KA, Eckel RH, Franklin BA, Gordon DJ, Krauss RM, Savage PJ, Smith SC Jr, Spertus JA, Costa F, American Heart Association, National Heart, Lung, and Blood Institute: Diagnosis and management of the metabolic syndrome: an American Heart Association/National Heart, Lung, and Blood Institute Scientific Statement. Circulation 2005, 112(17):2735-2752.

23. Lezak MD, Howieson DB, Loring DW: Neuropsychological Assessment. New York: Oxford University Press, 32004.

24. Waldstein SR, Katzel LI: Interactive relations of central versus total obesity and blood pressure to cognitive function. Int J Obes (Lond) 2006, 30(1):201-207.

25. Diabetes Control and Complications Trial/Epidemiology of Diabetes Interventions and Complications Study Research Group, Jacobson AM, Musen G, Ryan CM, Silvers N, Cleary P, Waberski B, Burwood A, Weinger K, Bayless M, Dahms W, Harth J: Long-term effect of diabetes and its treatment on cognitive function. N Engl J Med 2007, 356(18):1842-1852.

26. Strauss E, Spreen O, Sherman EMS: A Compendium of neuropsychological tests: administration, norms, and commentary. Oxford etc.: Oxford University Press, 32006.

27. Smith SM, Jenkinson M, Johansen-Berg H, Rueckert D, Nichols TE, Mackay CE, Watkins KE, Ciccarelli O, Cader MZ, Matthews PM, Behrens TE: Tract-based spatial statistics: voxelwise analysis of multi-subject diffusion data. Neuroimage 2006, 31(4):1487-1505.

28. Smith SM, Jenkinson M, Woolrich MW, Beckmann CF, Behrens TE, JohansenBerg H, Bannister PR, De Luca M, Drobnjak I, Flitney DE, Niazy RK, Saunders J, Vickers J, Zhang Y, De Stefano N, Brady JM, Matthews PM: Advances in functional and structural MR image analysis and implementation as FSL. Neuroimage 2004, 23(Suppl 1):S208-19.

29. Smith SM: Fast robust automated brain extraction. Hum Brain Mapp 2002, 17(3):143-155.

30. Andersson JLR, Jenkinson M, Smith S: Non-linear optimisation. 2007 [http://www.fmrib.ox.ac.uk/analysis/techrep], FMRIB technical report TR07JA1 from.

31. Andersson JLM, Jenkinson $M$, Smith S: Non-linear registration, aka Spatial normalisation. 2007 [http://www.fmrib.ox.ac.uk/analysis/techrep], FMRIB technical report TR07JA2 from.

32. Rueckert D, Sonoda LI, Hayes C, Hill DLG, Leach MO, Hawkes DJ: Non-rigid registration using free-form deformations: Application to breast MR images. IEEE Transactions on Medical Imaging 1999, 18(8):712-721.

33. Fazekas F, Chawluk JB, Alavi A, Hurtig HI, Zimmerman RA: MR signal abnormalities at $1.5 \mathrm{~T}$ in Alzheimer's dementia and normal aging. AJR Am J Roentgenol 1987, 149(2):351-356

34. Smith SM, Nichols TE: Threshold-free cluster enhancement: addressing problems of smoothing, threshold dependence and localisation in cluster inference. Neuroimage 2009, 44(1):83-98.

35. Kodl CT, Franc DT, Rao JP, Anderson FS, Thomas W, Mueller BA, Lim KO, Seaquist ER: Diffusion tensor imaging identifies deficits in white matter microstructure in subjects with type 1 diabetes that correlate with reduced neurocognitive function. Diabetes 2008, 57(11):3083-3089.

36. Forn C, Belloch V, Bustamante JC, Garbin G, Parcet-lbars MA, Sanjuan A, Ventura N, Avila C: A symbol digit modalities test version suitable for functional MRI studies. Neurosci Lett 2009, 456(1):11-14.

37. Madden DJ, Spaniol J, Costello MC, Bucur B, White LE, Cabeza R, Davis SW Dennis NA, Provenzale JM, Huettel SA: Cerebral white matter integrity mediates adult age differences in cognitive performance. $J$ Cogn Neurosci 2009, 21(2):289-302.

38. Sullivan EV, Rohlfing T, Pfefferbaum A: Quantitative fiber tracking of lateral and interhemispheric white matter systems in normal aging: Relations to timed performance. Neurobiol Aging 2008.

39. Madden DJ, Whiting WL, Huettel SA, White LE, MacFall JR, Provenzale JM: Diffusion tensor imaging of adult age differences in cerebral white matter: relation to response time. Neuroimage 2004, 21(3):1174-1181.

40. Arboix A, Marti-Vilalta JL: Lacunar stroke. Expert Rev Neurother 2009, 9(2):179-196.

41. Wardlaw JM, Sandercock PA, Dennis MS, Starr J: Is breakdown of the blood-brain barrier responsible for lacunar stroke, leukoaraiosis, and dementia? Stroke 2003, 34(3):806-812.

42. Arboix A: Stroke prognosis in diabetes mellitus. new insights, questions remain. Expert Rev Cardiovasc Theraphy 2009, 7:1181-5.

43. Rowe JW, Kahn RL: Human aging: usual and successful. Science 1987 237(4811):143-149.

\section{Pre-publication history}

The pre-publication history for this paper can be accessed here: http://www.biomedcentral.com/1471-2377/10/64/prepub

doi:10.1186/1471-2377-10-64

Cite this article as: Segura et al:: White matter fractional anisotropy is related to processing speed in metabolic syndrome patients: a casecontrol study. BMC Neurology 2010 10:64.

\section{Submit your next manuscript to BioMed Central and take full advantage of:}

- Convenient online submission

- Thorough peer review

- No space constraints or color figure charges

- Immediate publication on acceptance

- Inclusion in PubMed, CAS, Scopus and Google Scholar

- Research which is freely available for redistribution

Submit your manuscript at www.biomedcentral.com/submit
C Biomed Central 